Y. M. A. YAMADA,* Y. YUYAMA, T. SATO, S. FUJIKAWA, Y. UOZUMI (RIKEN CENTER FOR SUSTAINABLE RESOURCE SCIENCE, WAKO, INSTITUTE FOR MOLECULAR SCIENCE,

OKAZAKI, AND KYUSHU UNIVERSITY, FUKUOKA, JAPAN)

A Palladium-Nanoparticle and Silicon-Nanowire-Array Hybrid: A Platform for Catalytic Heterogeneous Reactions Angew. Chem. Int. Ed. 2014, 53, 127-131.

\title{
A Silicon Nanowire Array Stabilized Palladium-Nanoparticle Catalyst
}

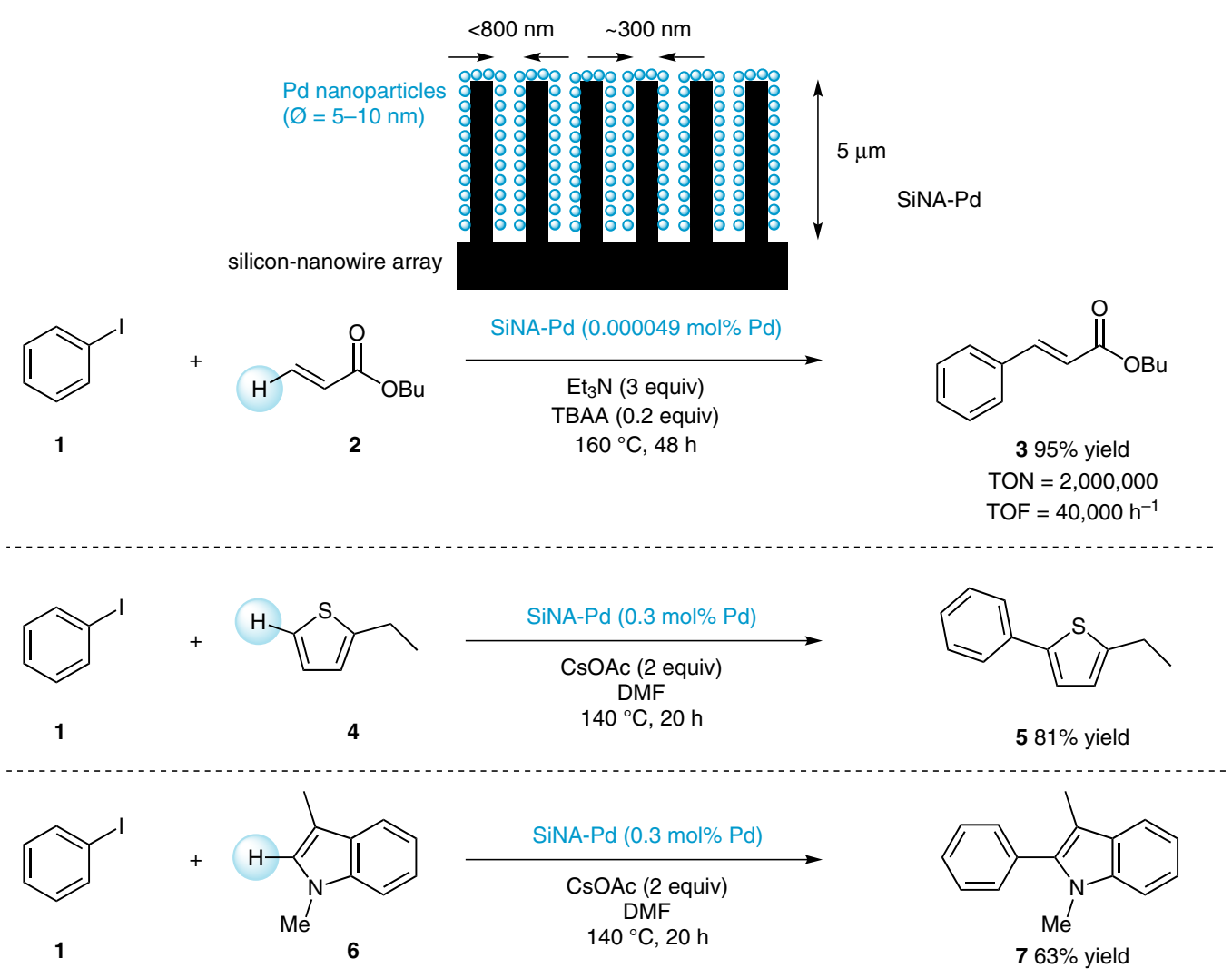

Significance: A silicon nanowire array stabilized palladium-nanoparticle catalyst (SiNA-Pd) for $\mathrm{C}-\mathrm{H}$ functionalization was developed. Thus, the Mizoroki-Heck reaction of iodobenzene (1, 50 mmol, $10.2 \mathrm{~g}$ ) and butyl acrylate (2, 2 equiv) proceeded in the presence of SiNA-Pd, $\mathrm{Et}_{3} \mathrm{~N}$, and tetrabutylammonium acetate (TBAA) to give butyl cinnamate (3) in 95\% yield (9.7 g). SiNA-Pd was applied to the $\mathrm{C}-\mathrm{H}$ functionalization reactions of thiophene $\mathbf{4}$ and indole $\mathbf{6}$, the hydrogenation of an alkene, and the hydrosilylation of an enone.
Comment: The turnover number (TON) of SiNAPd was $2 \times 10^{6}$ for the reaction of $\mathbf{1}$ and $\mathbf{2}$, which is the highest TON for any Mizoroki-Heck reaction with a heterogeneous catalyst. A thromboxane A2 synthesis inhibitor, (2E)-3-[4-(1H-imidazol-1-ylmethyl)phenyl]acrylic acid (ozagrel), was prepared via the SiNA-Pd-mediated Mizoroki-Heck reaction.

\section{Gategory}

Polymer-Supported Synthesis

\section{Key words}

silicon-nanowire array

palladium nanoparticles

Mizoroki-Heck reaction

C-H functionalization

Dol: 10.1055/s-0033-1340726; Reg-No.: Y01114SF 